SYNLETT Spotlight 278

This feature focuses on a reagent chosen by a postgraduate, highlighting the uses and preparation of the reagent in current research

\section{Iodoxybenzene $\left(\mathrm{PhIO}_{2}\right)$}

Compiled by Cai Zhang

Cai Zhang was born in Anhui Province, P. R. of China. He received his B.Sc. (2005) from Huaibei Coal Industry Teachers College, Anhui, P. R. of China. He is currently pursuing his M.Sc. under the tutelage of Professor Dacheng Yang at Southwest University, Chongqing, P. R. of China. His current research interests include the development of hypervalent iodine for application in organic synthesis.

College of Chemistry and Chemical Engineering, Southwest University, Chongqing 400715, P. R. of China

E-mail: stezh64@swu.edu.cn

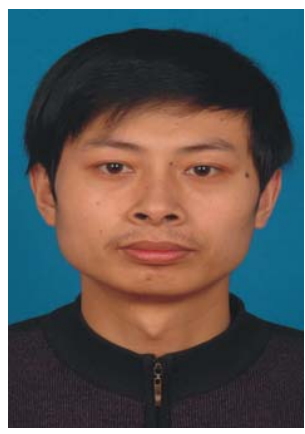

\section{Introduction}

Iodoxybenzene $\left(\mathrm{PhIO}_{2}, \mathrm{mp} 230{ }^{\circ} \mathrm{C}\right)$ is the first organic compound of iodine $(\mathrm{V})$ prepared by Willgerodt 100 years ago. ${ }^{1}$ Specifically, it can be prepared by disproportionation of iodosylbenzene under steam distillation. ${ }^{2}$ Ten years ago iodoxybenzene has been used for the synthesis of cadalenquinone, ${ }^{3 \mathrm{a}}$ unsaturated carbonyl compounds ${ }^{3 \mathrm{~b}-\mathrm{c}}$, oxodienes, ${ }^{3 \mathrm{~d}-\mathrm{e}}$, epoxides, ${ }^{3 \mathrm{f}}$ quinine imines, ${ }^{3 \mathrm{~g}}$ and sulfones. ${ }^{3 \mathrm{~h}}$ In this Spotlight recent applications using $\mathrm{PhIO}_{2}$ in organic syntheses are summarized.

\section{Preparation}

Iodoxybenzene $\left(\mathrm{PhIO}_{2}\right)$ can be directly prepared using commercial $40 \%$ peracetic acid or sodium periodate by dissolving iodobenzene in water (Scheme 1). ${ }^{4}$

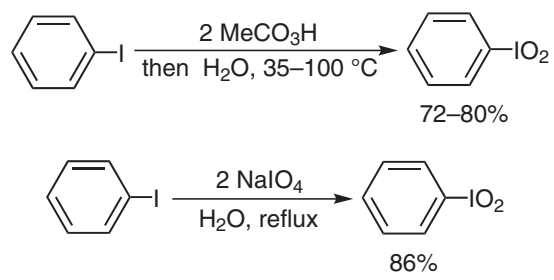

Scheme 1

\begin{abstract}
s
(A) Kita et al. show the solubilization and activation of $\mathrm{PhIO}_{2}$ by adding catalytic amounts of both cetyltrimethylammonium bromide $(\mathrm{CTAB})$ or $\mathrm{MgBr}_{2}$ and a chiral tartaric acid derivative. Both reagents were indispensable for the enhancement of chemical and optical yields in the oxidation of sulfides to sulfoxides. ${ }^{5}$
\end{abstract}

(B) The application of $\mathrm{PhIO}_{2}$ in the oxidation reaction of phosphorous, phosphorothiono and phosphoroseleno compounds into the corresponding $\equiv \mathrm{P}(\mathrm{O})$ analogues was demonstrated by Lopusinski et al. ${ }^{6 a}$ The direct conversion of ammonium dialkyl phosphoroselenoates into the dialkyl phosphoramidates using iodoxybenzene has been developed by the same group. ${ }^{6 \mathrm{~b}}$

SYNLETT 2009, No. 9, pp 1520-1521

Advanced online publication: 18.05.2009

DOI: 10.1055/s-0029-1217180; Art ID: V28408ST

(c) Georg Thieme Verlag Stuttgart · New York

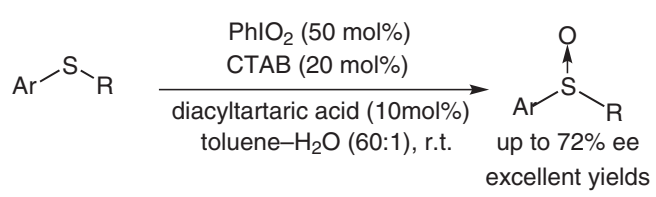

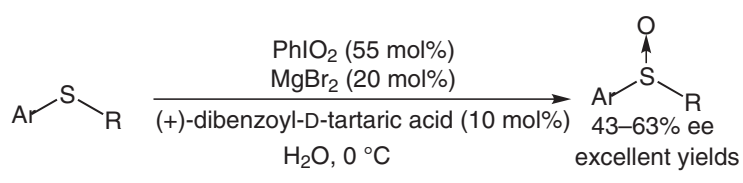

$$
\mathrm{X}=\text { lone electron pair, } \mathrm{S}, \mathrm{Se}
$$

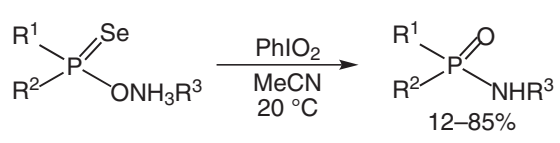


(C) The reaction performed between $N$-sulfinylphosphoramidate and $\mathrm{PhIO}_{2}$ in the presence of diethylphosphoramidate results in the formation of $N, N$-bis(diethylphosphor)sulfamide. ${ }^{7}$

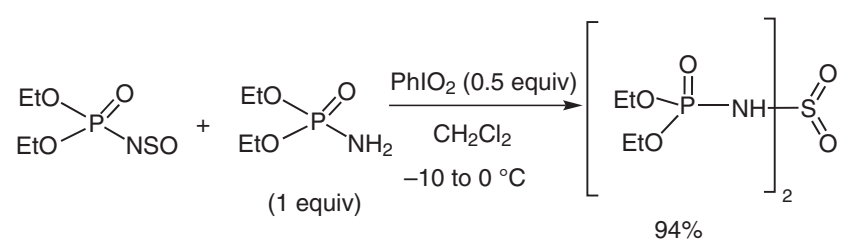

(D) Catalytic allylic oxidation of alkenes into enones and oxidation of aryl alkyl ketones into the corresponding ketoacids with a fluorous seleninic acid as catalyst in conjunction with $\mathrm{PhIO}_{2}$ as reoxidant have been developed by Zou and co-worker. ${ }^{8}$
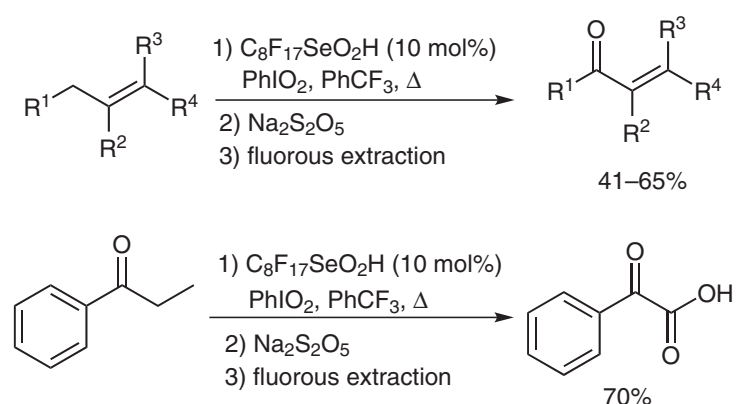

(E) Recently, air-driven conversion of alcohols into carbonyl compounds in water using catalytic amounts of $\mathrm{PhIO}_{2}$ has been reported by Liu and co-workers. ${ }^{9}$

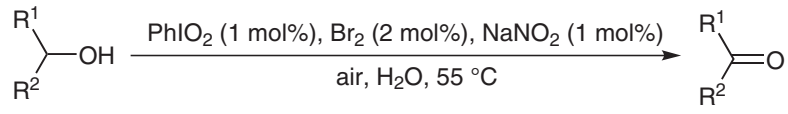

$42-98 \%$

\section{References}

(1) Willgerodt, C. Die Organischen Verbindungen mit Mehrwertigem Jod; Enke Verlag: Stuttgart, 1914.

(2) Willgerodt, C. J. Prakt. Chem. 1886, 33, 154.

(3) (a) Reddy, N.; Kesavulu, R. a. o.; G, S. K. Indian J. Chem., Section B: Org, Chem. Incl. Med. Chem. 1987, 26B, 920.

(b) Barton, D. H. R.; Crich, D. Tetrahedron 1985, 41, 4359.

(c) Gleiter, R.; Mueller, G. J. Org. Chem. 1988, 53, 3912.

(d) Künzer, H.; Sauer, G.; Wiechert, R. Tetrahedron 1989, 45, 6409. (e) Iida, T.; Nishida, S.; Chang, F. C.; Niwa, T.; Goto, J.; Nambara, T. Chem. Pharm. Bull. 1993, 41, 763. (f) Barret, R.; Sabot, J. P.; Pautet, F.; Cerf, P.; Daudon, M. Oxidation Communications 1989, 12, 55. (g) Barret, R.; Daudon, M.1990, 20, 1543. (h) Barret, R.; Pautet, F.; Bordat, P.; Tinland, B.; Daudon, M. Phosphorus, Sulfur and Silicon and the Related Elements 1989, 45, 31.

(4) (a) Sharefkin, J. G.; Saltzman, H. Org. Synth. 1963, 43, 65. (b) Kazmierczak, P.; Skulski, L.; Kraszkiewicz, L. Molecules 2001, 6, 881 .
(5) (a) Tohma, H.; Takizawa, S.; Watanabe, H.; Fukuoka, Y.; Maegawa, T.; Kita, Y. J. Org. Chem. 1999, 64, 3519.

(b) Tohma, H.; Takizawa, S.; Morioka, H.; Maegawa, T.; Kita, Y. Chem. Pharm. Bull. 2000, 48, 445.

(6) (a) Mielniczak, G.; Lopusinski, A. Synlett 2001, 505. (b) Mielniczak, G.; Lopusinski, A. Heteroatom Chem. 2003, 14, 121.

(7) Mielniczak, G.; Lopusinski, A. Heteroatom Chem. 2008, $19,530$.

(8) (a) Crich, D.; Zou, Y. Org. Lett. 2004, 6, 775. (b) Crich, D.; Zou, Y. J. Org. Chem. 2005, 70, 3309.

(9) Mu, R. Z.; Liu, Z. Q.; Yang, Z. J.; Liu, Z. G.; Wu, L. M.; Liu, Z. L. Adv. Synth. Catal. 2005, 347, 1333. 